\title{
Effect of implementing nursing care interventions to minimize infection among patients undergoing Intracranial Pressure monitoring
}

\author{
Asmaa Abd Elhafez Abd El-ghani ${ }^{1}$, Mogedda Mohamed Mehany ${ }^{2}$, Mohamed Abd El- Basset Ali ${ }^{3}$ MMona Abd Elaziem Ahmed $^{\mathbf{4}}$ \\ 1. Special Nursing in Assiut University Hospital, Assuit, Egypt. \\ 2. Assistant prof in Critical Care and emergency Nursing Department, Faculty of Nursing, Assuit University, Egypt. \\ 3. Assistant prof. Neurosurgical Department, Faculty of Medicine, Assuit University, Egypt. \\ 4. Lecturer in Critical Care and Emergency Nursing Department, Faculty of Nursing, Assuit University, Egypt.
}

\begin{abstract}
Introduction: Elevated intracranial pressure (ICP) can occur as a complication of neurosurgical emergencies including traumatic brain injury. Aim of this study: To evaluate the effect of implementing nursing care interventions to minimize infection among patients undergoing intracranial pressure monitoring. Design: Quasiexperimental research design was utilized in the study. Setting: This study was conducted at traumatic intensive care unit at Assiut university hospital. Patients: A convenient sample of 60 adult patients assigned into two equal group study and control group. Result: The results was successed in reducing of infection, there was a statistical significance difference between study and control group, Regarding to hyperthermia there were $(0.0 \%)$ of patients in the study group compared to $(26.7 \%)$ in control group the third day. Conclusion: Implementing nursing intervention successed in minimize infection among patients undergoing intracranial pressure monitoring. Recommendation: Apply nursing intervention to minimize infection among patients with Intracranial monitoring in traumatic ICU unit.
\end{abstract}

\section{Keywords: Nursing care, Minimize Infection \& Intracranial pressure.}

\section{Introduction:}

The pressure which created inside the skull is called intracranial pressure (ICP), the pressure of brain tissue and cerebrospinal fluid (CSF). The total of the volumes of brain and intracranial blood remains constant when the skull is intact because the brain is incompressible. The normal range of intracranial pressure 5 to $15 \mathrm{mmHg}$, ICP $>15 \mathrm{mmHg}$ is considered high, and it's a significant cause of secondary injury, which can lead to irreversible brain damage and death. Traumatic Brain Injury, intracerebral hemorrhage, subarachnoid hemorrhage, hydrocephalus, malignant infarction, cerebral edema, CNS infections, hepatic encephalopathy are among the situations for which ICP monitoring is indicated in any of these circumstances, ICP Monitoring in conjunction with other indicators can help to improve the management of elevated ICP. (Creech \& Johnson, 2017)

An ICP of 5 to $15 \mathrm{mmHg}$ is considered normal. There is no predetermined point at which intracranial hypertension treatment should begin, however values more than $20 \mathrm{mmHg}$ are routinely treated with the goal of maintaining an acceptable cerebral perfusion pressure. In neurosurgical practice, increased intracranial pressure (ICP) is a prevalent condition. It may develop as a result of cerebral mass lesions, Circulation problems in the cerebrospinal fluid (CSF), as well as more widespread intracranial pathologies. It can be either acute or chronic in nature. Intracranial pressure that rises rapidly or for a long time poses a major hazard to life. ICP elevations are dangerous because they can reduce brain perfusion and blood flow. The brain takes 50 to 55 milliliters of blood per $100 \mathrm{~g}$ of brain tissue to function properly (Morton et al., 2017).

It's important to figure out symptoms and signs if the symptoms a patient is experiencing can be attributable to something else, such a stroke, which raised ICP. Headache, Vomiting, Restlessness and Irritability, Elevated blood pressure, Decreased mental capacities, Confusion about time, location, and people as the pressure worsens, Double vision ,Pupils that don't react to light changes, Shallow breathing, Seizures, Decreased level of consciousness, coma are all signs of increased ICP (Carey, 2018).

Intracranial pressure (ICP) monitoring has been employed in the fields of neurosurgery and neurology for decades. There are several techniques: both invasive and noninvasive, such as ventriculostomy and micro transducers. Ventriculostomy is the gold standard in terms of accurate pressure monitoring, however tiny transducers are generally just as good. Both invasive approaches have a small risk of problems like bleeding and infection. Non-invasive techniques do not have the same risk of complications as invasive methods, but they do not measure ICP correctly enough to be utilized as a routine alternative to invasive assessment. (Holloway et al., 2016). 
Intracranial pressure monitoring measured by catheter is inserted into the brain parenchyma through a burr hole in this intra-parenchymal approach, which has a lower complication rate, infection rate, and no risk of catheter blockage or leakage. Because of the probe's modest diameter, there is less risk of neurological harm. Furthermore, transducer has a lower impact on measurement mistakes. When compared to patients treated without an ICP monitor, using an ICP monitor in the case of traumatic brain injury is associated with significantly lower mortality. Methods of ICP monitoring may also be linked to a number of problems. Infection risk, bleeding, blockage, placement difficulty, and malposition are some of them. (Smith et al., 2015).

A consequence of intracranial pressure monitoring devices is infection. Antimicrobial prophylaxis against intracranial pressure monitor (ICPM)-related infection has never been adequately characterized in terms of timing, duration, and role. In patients with ICPMs, risk variables were investigated, as well as the selection, duration, and timing of antibiotic prophylaxis. Infection is the most common consequence with ICP monitors, with reports ranging from $0 \%$ to $40 \%$ and an average of $10 \%$. Antibiotics given to patients prior to or during ICPM implantation had no effect on CSF infection rates. Patients with an ICPM duration of more than 5 days were shown to be at higher risk for infection at our facility, use of ventricular catheter, CSF leak, concurrent systemic infection, or serial ICPM. (Kanter et al., 2015).

Patients who require ICP monitoring should be cared for by trained critical care neuroscience nurses competent in neurologic assessment and management of the monitoring device. Patient assessment should include hourly monitoring for signs and symptoms associated with changing ICP, or more frequently as the clinical situation warrants. Notify the physician immediately if ICP exceeds established parameters. If no parameter is specified, notify the physician if ICP is $>20 \mathrm{mmHg}$. (Thompson, 2018).

Nursing interventions to reducing infection risk factors by using prophylactic antibiotics, Recognize how nursing care affects intracranial pressure, Determine each patient's ICP reference ranges based on physician directions, underlying pathophysiology and treatment plan, Keep an eye on pulmonary hygiene and the impact of therapies like suctioning and patient posture, Create a daily interdisciplinary care plan with individualized daily goals, As determined by the patient's condition, begin nursing consultations for skin management and hygiene, Nursing care should be scheduled at regular intervals to allow patients with high ICP to stabilized. (Thompson., 2018).
Significant of the study:

Despite increased awareness of hospital-acquired infection, and efforts to reduce its occurrence, the incidence continues to increase. It has been estimated that between $4 \%$ and $10 \%$ of hospitalized patients will become infected, particularly after entering the operation room or intensive care unit, (Between 2011 \& 2012), an estimated 53,700 of these Hospital acquired infection were surgical site infections are now considered to be the most common and costly , adding approximately 7 to 11 days to the expected post-surgical hospital stay and increasing perioperative morbidity and mortality( Milleret al., 2015).

During period from 2018-2019 60 Patients admitted to traumatic intensive care unit at Assiut university hospital with intracranial pressure monitoring by using Micro transducer catheter. (Hospital record of traumatic intensive care unit, 2019).

Aim of the study:

The aim of study was to evaluate effect of implementing nursing care interventions to minimize infection among patients who undergoing intracranial pressure monitoring.

\section{Hypothesis:}

- Patients who will received the interventions is will have fewer infection occurrence compared to control group.

- Patients who will receive the interventions is will have fewer complications occurrence compared to control group.

- Length of hospital stay will be shorter among the study groups compared to the control groups.

\section{Patients and Methods \\ Design:}

A quasi-experimental research design was used in the present study (study and control group).

Setting:

The study was conducted at traumatic intensive care unit at Assiut university hospital.

\section{Patients:}

A convenient sample of adult patients from both sex who were 60 patients were assigned into two equal group each group consist of 30 patients.

Study group: was received nursing intervention in addition to routine hospital care.

Control group was received routine hospital care.

Inclusion criteria: Patients admission in ICU, Age $>18$ years, GCS $<8$, both sexes (male and female), neurosurgical patients who need immediate postoperative ICP monitoring.

Exclusion criteria: patients admitted for surgery as surgical extradural hematoma and diabetic patients, penetrating brain injury, nonalberta resident and patients who died in the emergency department. 
Tools: Three tool were utilized in the study to developed by the researcher after review of literature to assess the patient conditions to form base line data. Tool one: Hemodynamic assessment tool: This tool divided into fifth parts:

Part (1): Patient demographic it include (patient code, age, sex, causes of injury, mortality rate).

Part (2): Assessment of patient's clinical data which included past medical history, medical diagnosis, length of ICU stay, date of admission.

Part (3): Hemodynamic assessment tool, which include heart rates, respiratory rate, body temperature, oxygen saturation.

Part (4): Level of consciousness by using Glass coma scale that was adopted from (Petridou \& Antonopoulos, 2017) it is used to give a reliable, objective way of recording the conscious level of a person for initial as well as subsequent assessment .it classified as :

- Mild, GCS $\geq 13$

- Moderate, GCS 9-12

- Sever, with GCS $\leq 8$

Part (5): laboratory investigation as Complete blood count, WBC, Hemoglobin, Blood sugar and CSF culture.

Tool two: Infection manifestation tool This tool was divided into two parts:

Part (I): Intracranial pressure (ICP) monitoring:

This tool was developed by the researcher after review of literatures, to assess ICP by using Micro transducer catheter:

Which consist of a miniature solid-state pressure transducer, mounted on a titanium case, at the end of a $100 \mathrm{~cm}$ flexible nylon tube. The transducer tip contains a silicon microchip with diffuse piezoelectric strain gauges. The micro sensor monitors ICP at the source intra-parenchymal, intra-ventricular or subdural, and the information is relayed electronically, rather than through a hydrostatic system or fibreoptics.

The Codman micro sensor is accurate, and stable, with a daily drift of $-0.13-0.11 \mathrm{~mm} \mathrm{Hg}$ per day. It is flexible, and can be tunneled beneath the scalp, preventing it from being easily broken. Its small size (a nominal outer diameter of $0.7 \mathrm{~mm}$ for the nylon vent tube and $1.2 \mathrm{~mm}$ for the transducer case). (Hong et al., 2016)

\begin{tabular}{|l|l|}
\hline \multicolumn{1}{|c|}{ Levels } & \multicolumn{1}{c|}{ ICP mmHg } \\
\hline Normal & $5-15$ \\
Mild & $16-20$ \\
Sever & $21-30$ \\
Very Sever & $>31$ \\
\hline
\end{tabular}

Part (II): Signs and symptom occurrence of infection:

This tool was developed by the researcher after review of literatures, Smith et al., (2019) to assess occurrence of infection consisted of fever, local signs include hotness and redness around catheter, complete blood count, leucocytes count, occurrence of CSF infection include meningitis and encephalitis . Tool Three: outcomes assessment tool: This tool developed to assess effect of implementing of nursing intervention of infection on patients outcomes include less of infection and other complication.

\section{Method}

Technique for data collection: The study was conducted throughout three main phases:

Preparatory phase:

This phase was involve:

1.Official and non-official permission to carry out the study was taken from the responsible authorities general, anesthesia and trauma intensive care unit at Assiut University after explanation the aim of study.

2.Development of the tool after reviewing the related literature.

3.Content validity of the tool and all necessary modification was established by panel of 6 expert who reviewed the instrument for clarity, relevance, comprehensive, understanding, applicability and easiness for administer modification will be required.

4.The reliability of the adapted tools had been done after reviewing literature using Cranach's coefficient alpha test as the following

5.Tool one: Part 1, Part 2, Part 3, Part 5 ( 0.850 )

6.Tool two : (0.870)

7.Tool three : $(0.790)$

8.A pilot study was carried out ( $10 \%$ of the sample) a number of 6 patients to test the clarity, validity and applicability of the tools.

Ethical consideration:

1.Research proposal was approved from Ethical committee in the faculty of nursing administration assuit university hospital.

2.There is no risk for study subject during application of the research.

3.The study was followed common ethical principles in clinical research.

4.The anonymity and confidentiality of response, voluntary participation and right to refuse to participate or withdrawal from the study without any rational at any time.

5.Informed consent was tokened from person participating study after explaining the nature and purpose of the study. 
6.Patient was assured that the data of this research will not be refused without second permission.

\section{Implementation phase:}

Data collection started from March 2018 until March 2019.for both group.

- Patient demographic and clinical data, hemodynamics, Glasgow coma scale and, laboratory investigation were assessed by using tool 1 from the patient record and conceders as a base line data.

- Assessment of intracranial monitoring by using Micro transducer catheter.

- Assessment of signs and symptoms of infection tool 2 part II.

For control group:

The control group was received the routine hospital nursing care.

\section{For study group:}

This group was received nursing intervention to minimize infection in patients who undergoing intracranial pressure monitoring which include:

Implementing of nursing intervention to minimize infection among the patients who undergoing intracranial pressure monitoring:

Immediate interventions should include securing the airway, maintaining adequate oxygenation and ventilation, and providing circulatory support as needed. Interventions to lower or stabilize ICP include elevating the head of the bed to thirty degrees, keeping the neck in a neutral position, maintaining a normal body temperature, and preventing volume overload. The patient must be stabilized before transport to radiology for brain imaging. A computed tomography (CT) scan is the most efficient test for confirming the diagnosis of increased ICP and determining its cause. In many cases, invasive ICP monitoring is required to guide medical and nursing interventions include: assess for patient history of any allergy, Assess vital signs and assessment of general condition of the patient, complete neurologic assessments, including the Glasgow Coma Scale (GCS), use aseptic technique when handling any part of the intracranial monitoring device or changing a dressing applied after surgery by physician ,keep wound insertion of the catheter clean and dry to prevent any infection around it, Check the drainage for cloudiness and blood, watch for sign of infection as fever, chills, neck rigidity ,Assess of any local signs of infection around wound site of ICP placement. such as loss of function of catheter or device in the affected area or palpable heat, monitor laboratory findings as white blood cells count an increasing WBC count indicates the body efforts to combat pathogens. Rate are normal (4.500 - 11.000), Monitoring of pulmonary hygiene by suctioning every two hours ,Maintain head of the bed elevation based on patient ' s underlying disease process to help control ICP ,Maintain adequate oxygenation by observing oxygen saturation, Maintain skin care change position every hourly to prevent bed sores ,Recording the reading of ICP measurement routinely every two hours .

\section{Evaluation phase:}

Each patients from both group was evaluated four time, first time concerning as base line data and for three days, by using this tools to explore the effect of implementing of nursing intervention to minimize infection, prevent complication and period of length of stay is shorter among patients who undergoing intracranial pressure monitoring on patients outcomes.

\section{Statistical analysis:}

The statistical analysis was carried out using SPSS version 23. The data collected were tabulated and analyzed by using frequency distribution, the percentage for qualitative variables. The chi-square test and independent samples t-test are used to determine significance for comparing two groups . 


\section{Results:}

Table (1): Distribution of the study and the control groups related to Socio demographic and clinical data of patients with ICP:

\begin{tabular}{|c|c|c|c|c|c|}
\hline & \multicolumn{2}{|c|}{ Study(n=30) } & \multicolumn{2}{|c|}{ Control $(n=30)$} & \multirow{2}{*}{ P. value } \\
\hline & No & $\%$ & No & $\%$ & \\
\hline \multicolumn{6}{|l|}{ Age by years } \\
\hline$<30$ years & 10 & 33.3 & 14 & 46.7 & \multirow{3}{*}{0.274} \\
\hline $30-40$ years & 14 & 46.7 & 8 & 26.7 & \\
\hline$<40$ years & 6 & 20.0 & 8 & 26.7 & \\
\hline Mean \pm SD & \multicolumn{2}{|c|}{$30.13 \pm 15.07$} & \multicolumn{2}{|c|}{$31.95 \pm 23$} & 0.718 \\
\hline \multicolumn{6}{|l|}{ Sex } \\
\hline Male & 20 & 66.7 & 24 & 80.0 & \multirow{2}{*}{0.382} \\
\hline Female & 10 & 33.3 & 6 & 20.0 & \\
\hline \multicolumn{6}{|l|}{ Causes of Injury } \\
\hline Fall down stair & 2 & 6.7 & 2 & 6.7 & \multirow{4}{*}{0.556} \\
\hline Fall from a high & 2 & 6.7 & 2 & 6.7 & \\
\hline Firearm & 2 & 6.7 & 0 & 0.0 & \\
\hline Motor car accident & 24 & 80.0 & 26 & 86.7 & \\
\hline \multicolumn{5}{|l|}{ Mortality Rate } & \multirow{3}{*}{$0.010 *$} \\
\hline Alive & 26 & 86.7 & 16 & 53.3 & \\
\hline Death & 4 & 13.3 & 14 & 46.7 & \\
\hline
\end{tabular}

Chi-square test,

*Significant difference at $p$. value $<0.05$,

**Significant difference at $p$. value $<0.01$.

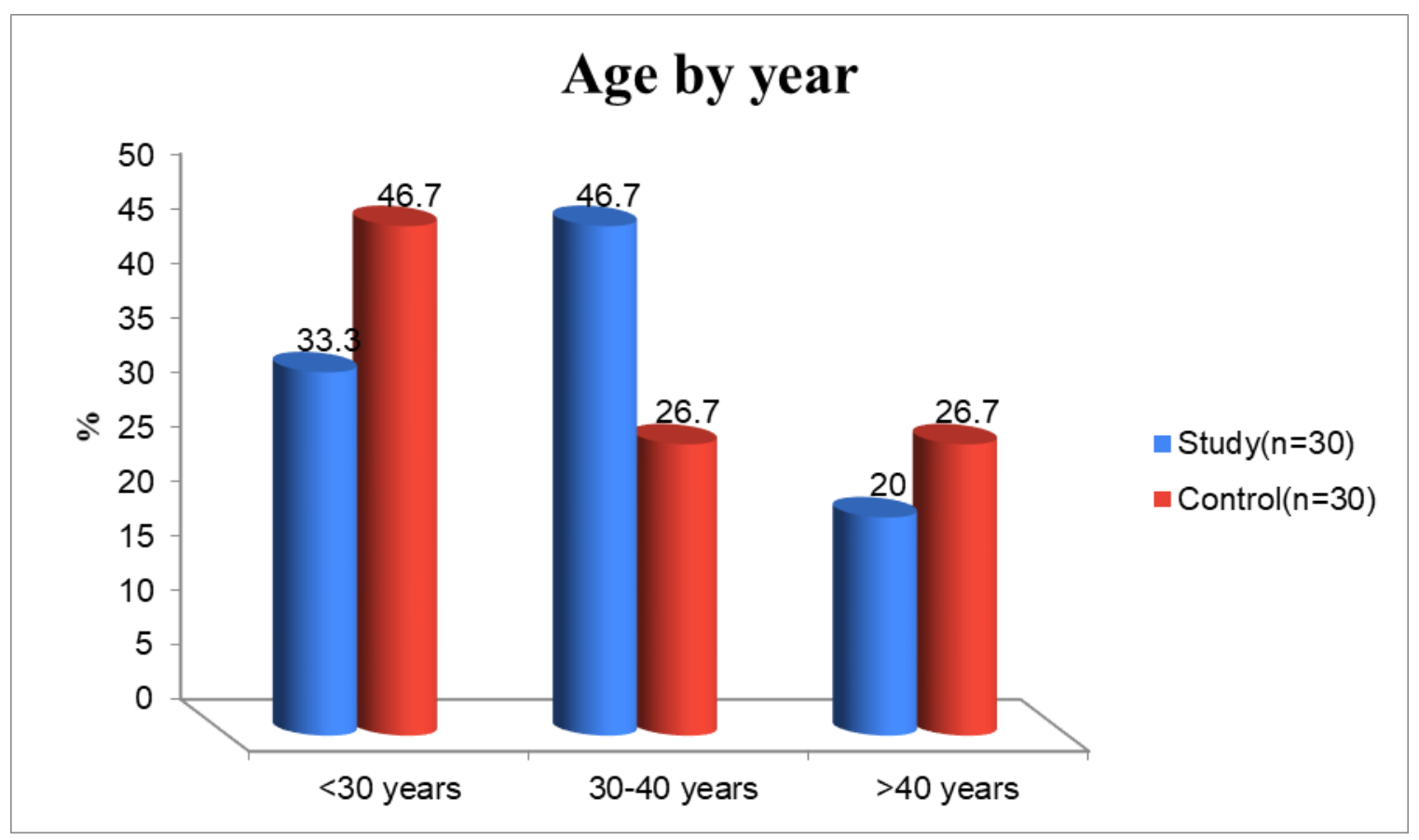

Fig (1): Age group in the study and the control groups related to socio demo graphic data of patients with ICP: 


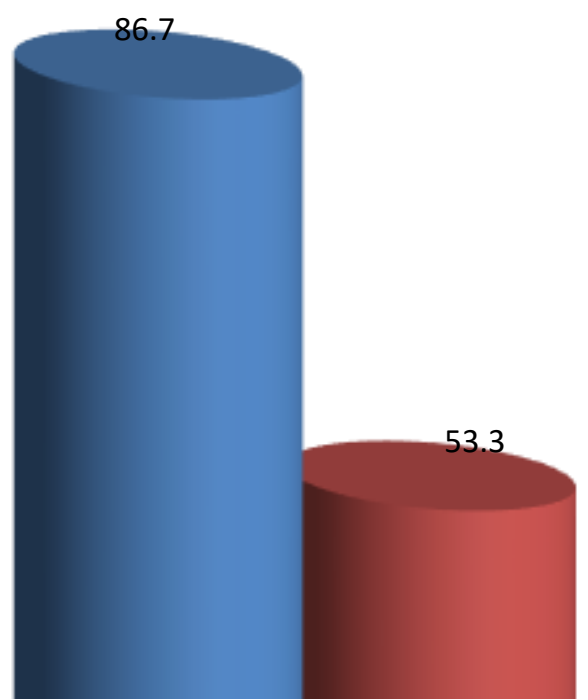

Fig (2): Comparison between the study and the control groups related to mortality rate at discharge from ICU

Table (2): Hemodynamic assessment of the study and the control groups:

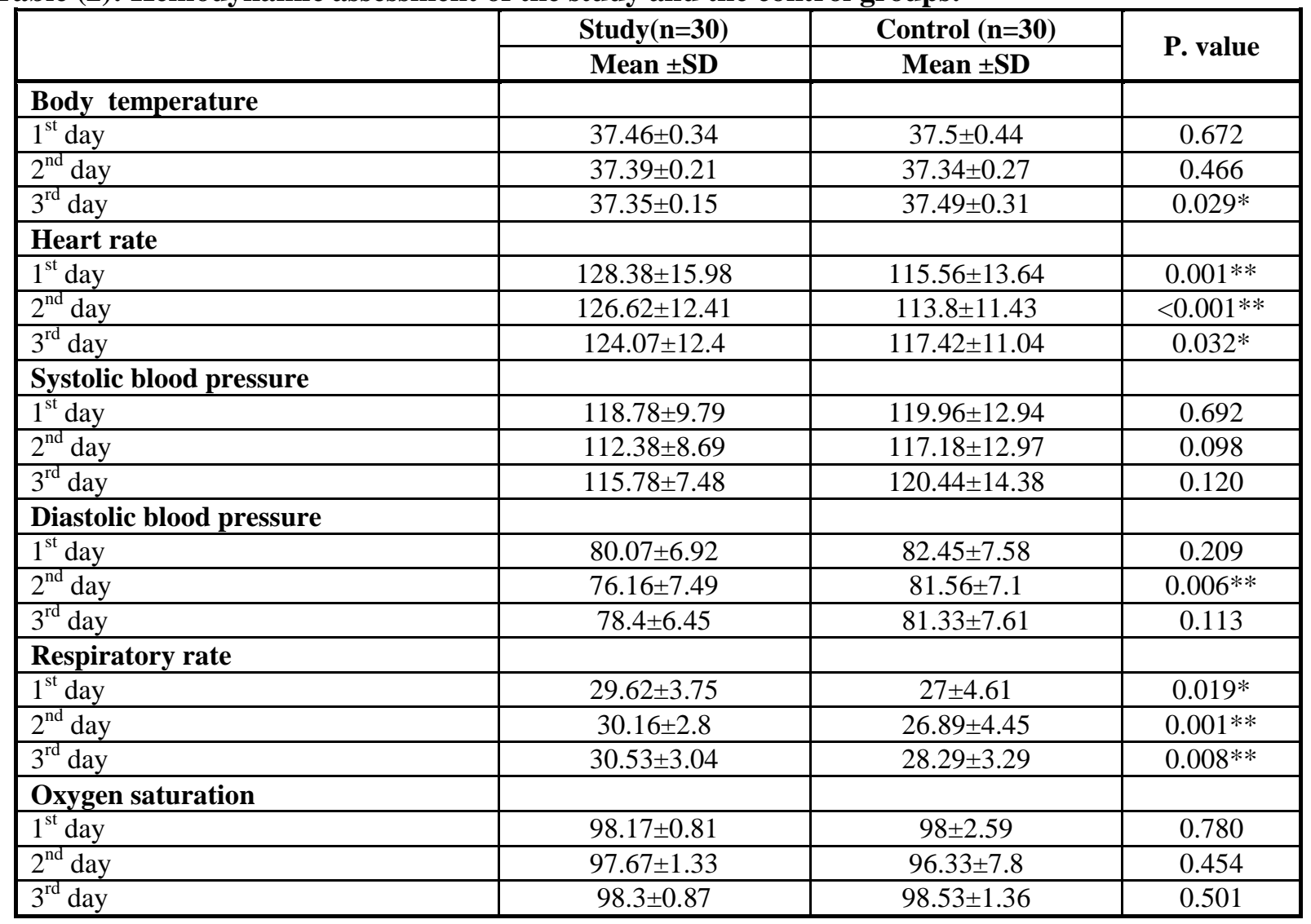

- Independent t-test

*Significant difference at $p$. value $<0.05$,

$* *$ Significant difference at p. value $<0.01$. 
Table (3): Laboratory investigation of the study and the control groups:

\begin{tabular}{|c|c|c|c|}
\hline & $\operatorname{Study}(n=30)$ & Control(n=30) & \multirow{2}{*}{ P. value } \\
\hline & Mean \pm SD & Mean \pm SD & \\
\hline \multicolumn{4}{|l|}{ WBC } \\
\hline $1^{\text {st }}$ day & $7.47 \pm 1.59$ & $9.51 \pm 0.61$ & $0.004 * *$ \\
\hline $2^{\text {nd }}$ day & $7.44 \pm 1.58$ & $9.73 \pm 0.97$ & $0.003 * *$ \\
\hline $3^{\text {rd }}$ day & $7.18 \pm 1.73$ & $9.45 \pm 0.98$ & $0.001 * *$ \\
\hline \multicolumn{4}{|l|}{ RBC } \\
\hline $1^{\text {st }}$ day & $4.4 \pm 0.51$ & $4.78 \pm 2.67$ & 0.662 \\
\hline $2^{\text {nd }}$ day & $4.05 \pm 0.88$ & $4.78 \pm 2.67$ & 0.422 \\
\hline $3^{\text {rd }}$ day & $4.38 \pm 0.57$ & $4.78 \pm 2.68$ & 0.649 \\
\hline \multicolumn{4}{|l|}{ Hemoglobin } \\
\hline At admission & $11.99 \pm 1.56$ & $10.62 \pm 1.79$ & $0.003 * *$ \\
\hline $3^{\text {rd }}$ day & $11.76 \pm 2.07$ & $10.64 \pm 1.82$ & $0.032 *$ \\
\hline \multicolumn{4}{|l|}{ Blood sugar } \\
\hline $1^{\text {st }}$ day & $7.57 \pm 5.65$ & $11.05 \pm 1.1$ & 0.250 \\
\hline $2^{\text {nd }}$ day & $7.27 \pm 2.63$ & $11 \pm 1.15$ & $0.017 *$ \\
\hline $3^{\text {rd }}$ day & $6.12 \pm 3.26$ & $11 \pm 1.15$ & $0.012 *$ \\
\hline
\end{tabular}

- Independent t-test $\quad *$ Significant difference at p. value $<0.05, \quad * *$ Significant difference at p. value $<0.01$

Table (4): Comparison between the study and the control groups related to Intracranial Pressure ICP

\begin{tabular}{|l|c|c|c|}
\hline \multirow{2}{*}{ ICP Monitoring } & Study $(\mathbf{n}=\mathbf{3 0})$ & Control(n=30) & \multirow{2}{*}{ P. value } \\
\cline { 2 - 3 } & Mean \pm SD & Mean \pm SD & \\
\hline $1^{\text {st }}$ day & & & 0.143 \\
\hline $2^{\text {nd }}$ day & $22.7 \pm 2.97$ & $23.87 \pm 3.1$ & 0.073 \\
\hline $3^{\text {rd }}$ day & $21.33 \pm 4.05$ & $22.93 \pm 2.56$ & $0.024^{* *}$ \\
\hline $4^{\text {th }}$ day & $19.67 \pm 4.59$ & $22.31 \pm 3.6$ & $0.004^{* *}$ \\
\hline $5^{\text {th }}$ day & $18.7 \pm 1.88$ & $21.31 \pm 3.28$ & $0.024^{*}$ \\
\hline
\end{tabular}

- Independent t-test *Significant difference at p. value $<0.05 * *$.

*Normal range of intracranial pressure monitoring in adults $10-15 \mathrm{~mm} \mathrm{Hg}$ in adult patients.

Table (5): Comparison between the Study and the control groups related to Glasgow come Scale

\begin{tabular}{|l|c|c|c|}
\hline \multirow{2}{*}{ Glasgow come Scale } & Study $(\mathbf{n}=\mathbf{3 0})$ & Control(n=30) & \multirow{2}{*}{ P. value } \\
\cline { 2 - 4 } & Mean \pm SD & Mean \pm SD & \\
\hline $1^{\text {st }}$ day & & & $0.015^{*}$ \\
\hline $2^{\text {nd }}$ day & $5.00 \pm 3.84$ & $2.83 \pm 3.22$ & $0.006^{* *}$ \\
\hline $3^{\text {rd }}$ day & $5.20 \pm 3.75$ & $2.80 \pm 2.98$ & $0.008^{* *}$ \\
\hline
\end{tabular}

- Independent t-test $*$ Significant difference at p. value $<0.05 * *$.

Table (6): Comparison between the study and the control groups related to length of stay of patients in ICU.

\begin{tabular}{|c|c|c|c|c|c|}
\hline & \multicolumn{2}{|c|}{ Study } & \multicolumn{2}{|c|}{ Control } & \multirow{2}{*}{ P.value } \\
\hline & No & $\%$ & No & $\%$ & \\
\hline \multicolumn{6}{|l|}{ Length of ICU stay } \\
\hline Less than 10 days & 26 & 86.7 & 8 & 26.7 & \multirow{3}{*}{$<0.001 * *$} \\
\hline From 10-20 days & 4 & 13.3 & 6 & 20.0 & \\
\hline More than 20 days & 0 & 0.0 & 16 & 53.3 & \\
\hline Mean $\pm \mathrm{SD}($ range $)$ & \multicolumn{2}{|c|}{$6.13 \pm 4.81(3-20)$} & \multicolumn{2}{|c|}{$29.46 \pm 20.69(3-70)$} & $<0.001 * *$ \\
\hline
\end{tabular}

Chi-square test, $\quad *$ Significant difference at p. value $<0.05, \quad * *$ Significant difference at p. value $<0.01$ 


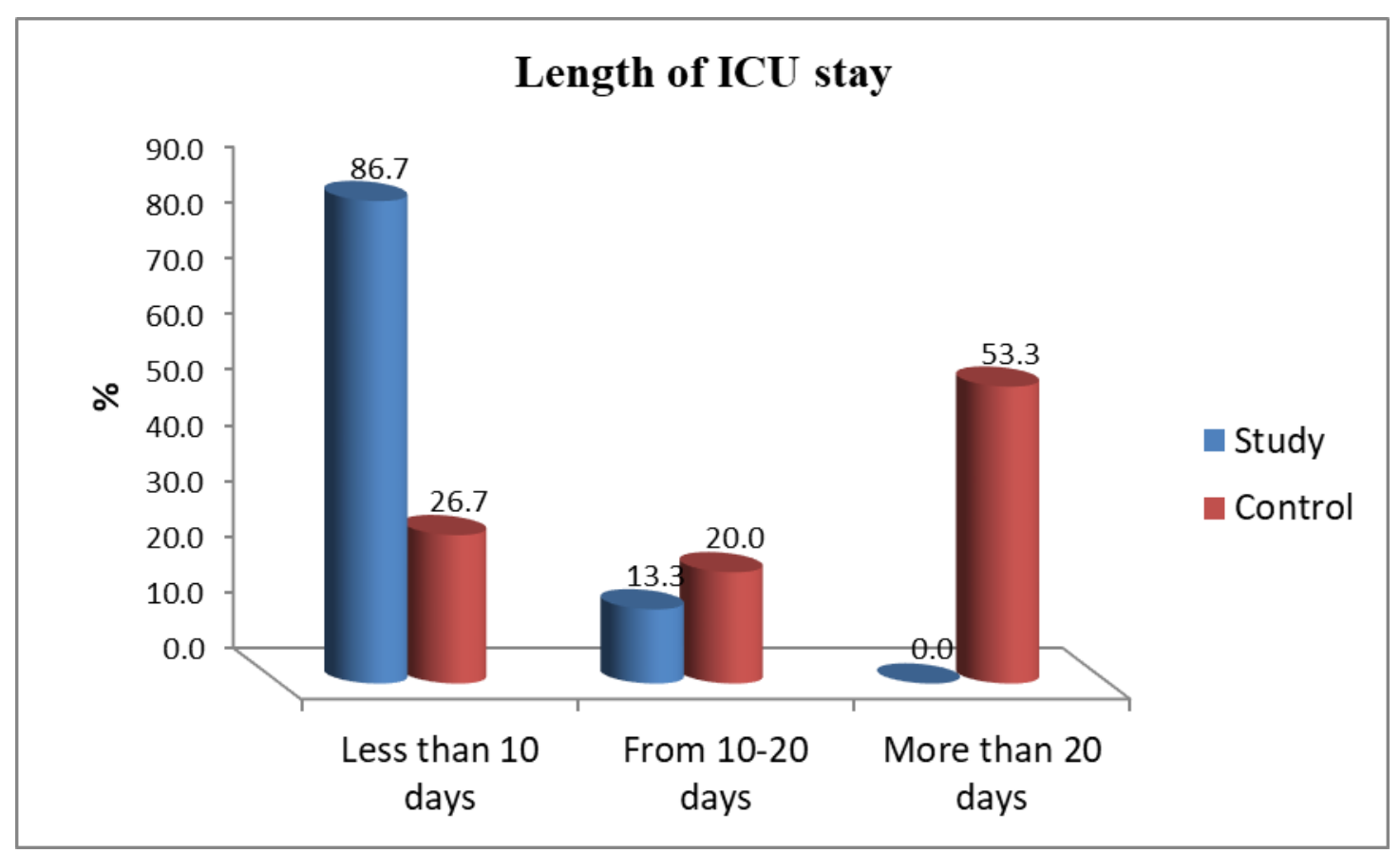

Fig (3): Comparison between the study and the control groups related to length of stay of patients in ICU.

Table (7): Percent of distribution of the study and the control groups related to signs of infection:

\begin{tabular}{|c|c|c|c|c|c|}
\hline & \multicolumn{2}{|c|}{ Study $(n=30)$} & \multicolumn{2}{|c|}{ Control $(n=30)$} & \multirow{2}{*}{ P. value } \\
\hline & No & $\%$ & No & $\%$ & \\
\hline \multicolumn{6}{|c|}{ Hyperthermia } \\
\hline $1^{\text {st }}$ day & 8 & 26.7 & 12 & 40.0 & 0.412 \\
\hline $2^{\text {nd }}$ day & 6 & 20.0 & 15 & 50.0 & $0.030^{*}$ \\
\hline $3^{\text {rd }}$ day & 3 & 10.0 & 13 & 43.3 & $0.008 * *$ \\
\hline $4^{\text {th }}$ day & 0 & 0.0 & 8 & 26.7 & $0.007 * *$ \\
\hline \multicolumn{6}{|c|}{ Hotness } \\
\hline $1^{\text {st }}$ day & 4 & 13.3 & 6 & 20 & 0.488 \\
\hline $2^{\text {nd }}$ day & 0 & 0.0 & 2 & 6.7 & 0.150 \\
\hline $3^{\text {rd }}$ day & 0 & 0.0 & 2 & 6.7 & 0.150 \\
\hline $4^{\text {th }}$ day & 0 & 0.0 & 0 & 0 & - \\
\hline \multicolumn{6}{|c|}{ Redness } \\
\hline $1^{\text {st }}$ day & 0 & 0.0 & 8 & 26.7 & $0.002 * *$ \\
\hline $2^{\text {nd }}$ day & 0 & 0.0 & 4 & 13.3 & $0.038^{*}$ \\
\hline $3^{\text {rd }}$ day & 0 & 0.0 & 2 & 6.7 & 0.150 \\
\hline $4^{\text {th }}$ day & 0 & 0.0 & 0 & 0 & - \\
\hline \multicolumn{6}{|c|}{ Secretion } \\
\hline $1^{\text {st }}$ day & 2 & 6.7 & 2 & 6.7 & 1.000 \\
\hline $2^{\text {nd }}$ day & 0 & 0.0 & 2 & 6.7 & 0.150 \\
\hline $3^{\text {rd }}$ day & 0 & 0.0 & 0 & 0.0 & - \\
\hline $4^{\text {th }}$ day & 0 & 0.0 & 0 & 0.0 & - \\
\hline \multicolumn{6}{|c|}{ Tenderness } \\
\hline $1^{\text {st }}$ day & 2 & 6.7 & 0 & 0.0 & 0.150 \\
\hline $2^{\text {nd }}$ day & 2 & 6.7 & 4 & 13.3 & 0.389 \\
\hline $3^{\text {rd }}$ day & 2 & 6.7 & 4 & 13.3 & 0.389 \\
\hline $4^{\text {th }}$ day & 2 & 6.7 & 4 & 13.3 & 0.389 \\
\hline
\end{tabular}

- Chi-square test, $\quad *$ Significant difference at $p$. value $<0.05, \quad * *$ Significant difference at $p$. value $<0.01$ 
Table (1): Shows the mean of age in study and control group $(30.13 \pm 15.07$ and31.95 \pm 23$)$ respectively. Show a highly percent of male patients in study and control group were $(66.7 \%)$ versus $(80 \%)$ respectively, It show that there was no significant difference between two groups ( $p$ value $<0.05)$, it show a highly percent of motor car accident in control and study group were $(86.7 \%$ and $80.0 \%)$ respectively. According to mortality rate it show there a statistical significant difference between the study and control group were $(86.7 \%)$ of study group alive and $(53.3 \%)$ of control group versus $(13.3 \%)$ of study group death and (46.7\%) of control group respectively.

Fig (1): Shows a higher percent of study group $(46.7 \%)$ of age from 30- 40 years and (46.7\%) of control group from 18-30 years.

Fig (2): Shows mortality rate were alive $(86.7 \%)$ of study group and $(53.3 \%)$ of control group were death. According to mortality rate of death $(46.7 \%)$ of control and (13.3\%) of study group.

Table (2): Shows hemodynamic status ( routine vital signs ) of study and control groups, According to body temperature there were statistical significant difference between study and control groups in the $\left(3^{\text {rd }}\right.$ day $)$ and ( $\mathrm{p}$ value $\left.0.029^{*}\right)$. No significant difference were found in the $\left(1^{\text {st }}\right.$ and $2^{\text {nd }}$ day) and ( $p$ value $>0.05$ ). According to pulse, it noticed that were statistical significant difference between two groups in three days ( $\mathrm{p}$ value $<0.05$ ). According to systolic blood pressure, there were no statistical significant difference between study and control group in the three days( $p$ value >0.05).According to diastolic blood pressure, there were statistical significant difference between study and control group in the $\left(2^{\text {nd }}\right.$ day $),\left(\mathrm{p}\right.$ value $\left.0.006^{*}\right)$.According to respiratory rate there were statistical significant difference between study and control group in three days ( $\mathrm{p}$ value $<0.05)$. According to oxygen saturation, it noticed that there on statistical difference between study and control group in three days ( $p$ value $>0.05$ ).

Table (3): Shows WBC, there were a statistical significant difference between study and control group in three days ( $\mathrm{p}$ value $<0.05$ ), According to $\mathrm{RBC}$, there were no statistical significant difference ( $\mathrm{p}$ value >0.05), According to Hemoglobin, there were significant difference between study and control group ( $p$ value $<0.05$ ). According to blood sugar, there were significant difference between study and control group in the $\left(2^{\text {nd }}\right.$ day and $3^{\text {rd }}$ day) ( $\mathrm{p}$ value $0.017^{*}$ and $0.012^{*}$ ) versus $1^{\text {st }}$ day there were no statistical significant difference ( $p$ value $>0.05$ )

Table (4): Shows ICP monitoring of study and control group, that there were a statistical significant difference between study and control group in the last three days $\left(\mathrm{p}<0.01^{\prime}\right.$ respectively .versus in first two days there were no statistical significant difference between both group.

Table (5): Shows Glasgow Coma Scale, were a statistical significant difference in three days and patient not oriented ( $\mathrm{p}$ value $<0.05$ )

Table (6): Shows mean of length of ICU stay in hospital $(6.13 \pm 4.81$ and $29.46 \pm 20.69)$ of study and control group.

Fig (3): Shows $(86.7 \%)$ of study group from (less than 10 days) still in hospital versus $(53.3 \%)$ of control group still (more than 20 days).

Table (7): Shows hyperthermia, there were a statistical significant difference between two groups in the last three days ( $\mathrm{p}$ value $<0.05$ ), versus first day there no a statistical significant difference between study and control group .related to redness, there were a statistical significant in the study and control group in the $\left(1^{\text {st }}\right.$ day and $2^{\text {nd }}$ day) ( $p$ value $0.002 * *$ and $0.038 *)$ versus in the $\left(3^{\text {rd }}\right.$ day and $4^{\text {th }}$ day $)$ ( $\mathrm{p}$ value >0.05). Regarding hotness, secretion and tenderness, there was no a statistical significant difference between the two groups ( $\mathrm{p}$ value $>0.05$ ).

\section{Discussion:}

Increased intracranial pressure (ICP) can be an indication of a brain tumors, an infection, or even a subarachnoid hemorrhage caused by a fall The brain, intravascular blood, and cerebrospinal fluid fill the skull (CSF). These components adjust to each other through an auto-regulation process, resulting in a constant ICP. When any of these quantities cease to be regulated, pressure inside the skull increases, resulting in an increase in ICP. A temporary brain damage, long-term coma , or even death might occur if therapy is delayed or if intracranial pressure is not reduced. (Pinto, Tadi \& Adeyinka 2019).

Effect of nursing intervention on reducing infection in patients undergoing intracranial pressure monitoring, including checking drainage for cloudiness and blood, watching for signs of infection such as fever, chills, and neck rigidity, and assessing any local signs of infection around the wound site of ICP placement. Such is a loss of function, Assess vital signs, secure the airway, ensure appropriate oxygenation and ventilation, and provide circulatory support as needed. Elevating the head of the bed to thirty degrees, keeping the neck in a neutral position, maintaining a normal body temperature, and avoiding volume overload are all ways to lower or stabilize ICP (Robin Haskell, 2020).

The study aimed to minimize infection among the patients who undergoing to intracranial pressure monitoring. 
This discussion will cover the main result finding as follow:

In terms of length of stay, the majority of the study group spent fewer than 10 days in the ICU, whereas half of the control group spent more than 20 days. This is consistent with the findings of (Aiolfi, et al., 2017), who found that daily intervention improved patient health and reduced hospital stay.

According to mortality rate ,The present study shows that more than half of the patients from study group were alive versus nearly half patients of the control group were death, This agree with ( Aiolfi et al., 2017) who reported that ICP monitoring utilization was associated with lower mortality rate and using ICP monitoring was linked to a decreased death rate.

In terms of intracranial pressure monitoring, the results of this observational study revealed that there was a statistically significant difference in intracranial pressure monitoring between the study and control groups in the last three days of the study period. This contrasts with (Aiolfi et al., 2017) who found that variability in ICP monitoring rates contributed only modestly to variability in ICP monitoring rates. (Mayhall et al., 2017) discovered a higher risk of infection in patients who had an ICP catheter in place for more than 5 days or more of monitoring, and an increased risk of infection occurred in our patients. (Lyons et al., 2016) discovered that the type of intracranial pressure monitoring used had a significant relationship with the development of infection. CNS infection with elevated cell counts in cerebrospinal fluid can also induce greater intracranial pressure, in addition to insertion of the catheter having a higher incidence of infection due to deep brain penetration.

In terms of signs of infection, there was a statistical significance difference between the study and control groups in terms of signs of infection (hyperthermia) in moreover; there was a statistical significance difference between the study and control groups in terms of signs of infection, but the patients' condition improved, so this may be in the study group. This is in agreement with (Young et al., 2018). who reported that ICP monitoring placement site is a safe procedure with a low-risk profile, ( Garner, et al., 2018 ) who report that CSF infection must have met at fever in the absence of other recognized cause with institution of appropriate antimicrobial treatment and report that CSF infection was adapted from the centers for disease control guidelines, CSF infection must have met at fever in the absence of other recognized cause with institution of appropriate antimicrobial therapy. Antibiotics given to patients before or after intracranial pressure monitoring installation did not reduce the incidence of CSF infection, according to (Classen et al., 2016). At our hospital, patients who had been monitored for intracranial pressure for a long time were shown to be at a higher risk of infection.

\section{Limitation of the study:}

CSF culture not available due to highly cost.

\section{Conclusion}

Applying nursing care interventions helps in minimizing infection aming patients with intracranial pressure.

\section{Recommendation:}

Based on the result of present study the following recommendation: Apply nursing intervention to minimize infection in trauma intensive care unit, Develop training program for nurses in traumatic intensive care unit about nursing intervention to minimize infection among patients with intracranial monitoring.

\section{References:}

- Aiolfi, E Benjamin, D Khor, K Inaba, L \& Lam, (2017): Brain Trauma Foundation Guidelines for Intracranial Pressure Monitoring: Compliance and Effect on Outcome.

- Carey, E, (2018): Increased Intracranial Pressure', Health line, viewed7September 2020, https://www.healthline.com/health/increasd intracranial-pressure.

- Classen DC, Evans RS, \& Pestotnik SL, (2016): The timing and prophylactic administration of antibiotics and the risk of surgical-wound infection. N Engl J Med 326:281-286.

- Creech \& Johnson, Narayan RK, Kishore PRS, \& Becker DP, (2017): Intracranial pressure Neurosurgical 56: 650-659.

- Garner JS, Jarvis WR, \& Emori TG, (2018): CDC definitions for nosocomial infections. Am $\mathbf{J}$ Infect Control 16:128-140.ction: the effect of monitoring duration and catheter exchange in Neurological patients J 85:419-424?

- Heyland DK, Mac Donald S, \& Keefe L, (2019): Total parenteral nutrition in critically ill patient: a meta-analysis. JAMA. , 280.

- Hong WC, Tu YK, Chen YS, Lien LM, \& Huang SJ, (2016): Subdural intracranial pressure monitoring in severe head injury: Clinical experience with the Codman Micro Sensor. Surg Neurol, 66 Suppl 2:813.

- Holloway KL, Barnes T, \& Choi S, (2016): Ventriculostomy infection: the effect of monitoring duration and catheter exchange in $584 \mathrm{~J}$ Neurosurgical 85:419-424. 
- Kanter RK, Weiner LB, \& Patt AM, (2015): Infectious complications and duration of ICP monitoring. Critical Care Medicine 13:837-839.

- Lyons MK \& Meyer FB (2016): Cerebrospinal fluid physiology and the management of increased intracranial pressure. Mayo Clinical Procedure 65:684-707.

- Morton, P.G., Fontaine, D.K., Hudak, C.M. \& Gallo, B.M. (2017): Critical Care Nursing, a Holistic Approach, $8^{\text {th }}$ Edition.

- Mayhall GC, Archer NH, \& Lamp VA, (2017): Ventriculostomy related infection: a prospective epidemiologic study .N Engl F Med 553-559.

- Miller JD, Bobo H, \& Kapp JP, (2015): Intracranial pressure reading for bolts. Neurosurgery, 19:253-5.

- Pinto, V L, Tadi, P \& Adeyinka, A (2019): 'Increased Intracranial Pressure', StatPearls, viewed 7 September 2020.

- Robin Haskell, (2020): MSN, RN, CRNP Increased Intracranial Pressure (ICP): What Nurses Need to Know neurosurgical 534-567.

- Petridou \& Antonopoulos, (2017): Injury Epidemiology, international Encyclopedia of Public Health, 258-274.

- Smith, E.R. \& Amin-Hanjani, s (2019): Evaluation and management of elevated intracranial pressure in adults up to date. Retrieved from: https://www.up to date .com /contents/evaluation and management -of -elevated- intracranial pressure-in -adults.

- Thompson, H.J. (2018): Care of the Patient Undergoing Intracranial Pressure Monitoring/ External Ventricular Drainage or Lumbar Drainage. AANN Clinical Practice Guideline Series. Retrieved from: https://www.bmc.org/sites/default/files/Patient_Car e/Specialty_Care/Stroke_and_Cerebrovascular_Cen ter/Medical_Professionals/Protocols.

- Young B, Ott L, \& Dempsey R, (2018): Relationship between admission hyperglycemia and neurologic outcome of severely brain-injured patients. Ann Surg, 466-473. 